\title{
ФИЛОСОФИЯ
}

DOI: $10.17805 /$ ggz.2019.3.8

\section{Ответ на вопрос: что такое постправда? Перспектива проблематологии*}

\author{
А. В. Морозов \\ Институт философии РАН
}

В статье поднимается вопрос о том, какими могут быть основания у рациональности и духовно-нравственных ценностных установок в ХХІ в. в мире, отмеченном господством так называемой «политики постправдыл». Для ответа автор обращается к концепщиям постправды теоретика риторики Брюса Маккомиски и сочиального эпистемолога Стива Фуллера и производит их сравнение, более подробно останавливаясь на первой.

С точки зрения Маккомиски, ситуация постправды отличается от более ранней ситуачии изменением преобладающего риторического режима - если ранее «брехня» (термин Гарри Франкфурта) политических деятелей, СМИ и медиа затрагивала этос и пафос коммуникащии, оставляя логос по большей части нетронутым, то в наши дни, после референдума о Брексите и избрания Дональда Трампа президентом США, логос оказался подвергнут обесиениванию. Проанализировав подход Маккомиски с учетом кониепиии Фуллера, автор делает вывод, что рассмотрение предмета первым недостаточно, поскольку постправда обладает не только отрицательным (как полагает Маккомиски), но и положительным измерением.

Для того чтобы описать оба данных измерения, автор прибегает $\kappa$ риторической теории Мишеля Мейера - проблематологии. С ее помощью он демонстрирует, что упор, который Маккомиски делает на логосе, избыточен и что «объективные факты» (якобы оказавшиеся под угрозой в мире постправды) включают в себя не только логос, но и остальные риторические компонентыл.

Автор приходит к заключению, что проблематологическая парадигма с ее акцентом на вопромании способна дать основание для ращиональности и нравственных иенностей в мире, вышедшем из «состояния постмодерна».

\footnotetext{
Статья подготовлена в рамках работы по Программе фундаментальных исследований РАН «Многофакторные вызовы и риски перехода к новому этапу научно-технологического и экономического развития России: фундаментальные и прикладные проблемы». The article was prepared as part of the work on the Fundamental Research Program of the RAS "Multifactor Challenges and Risks of Transition to a New Stage of the Scientific, Technological and Economic Development of Russia: Fundamental and Applied Problems”.
} 
Ключевые слова: иенностные основания; постправда; брехня; истина; риторика; проблематология; постмодернизм; постпостмодернизм; основания рациональности

\section{Answering the Question: What is the Post-Truth? A Problematological Approach \\ A. V. Morozov \\ Institute of Philosophy, Russian Academy of Sciences}

The article raises the following question: what could be grounds for rationality and foundations for spiritual and moral value systems in the 21st century world that is marked by the dominance of the so-called "post-truth politics"? In order to answer this question, the author addresses two conceptions of post-truth, proposed by the rhetorical theorist Bruce McComiskey and social epistemologist Steve Fuller, and compares them highlighting the first one.

According to McComiskey, the post-truth condition differs from the earlier situation by the change of the prevailing rhetorical regime. Whereas previously the "bullshit" (Harry Frankfurt's term) of politicians and mass media was affecting the ethos and pathos of communication, leaving logos mostly intact, then nowadays, after the Brexit referendum and the U.S. presidential election of Donald Trump, logos has been denigrated. Having analyzed McComiskey's approach in the light of Fuller's conception, the author concludes that the former's treatment of the subject is insufficient, because post-truth has not merely a negative (as McComiskey believes) but also a positive dimension.

In order to describe both these dimensions, the author uses Michel Meyer's rhetorical theory - problematology. It helps to demonstrate that McComiskey's emphasis on logos is excessive and that the "objective facts" (allegedly threatened in the post-truth world) include not only logos but also other rhetorical elements.

The author concludes that the problematological paradigm with its focus on questioning can provide grounds for rationality and moral values in the world that has emerged from the "postmodern condition".

Keywords: value foundations; post-truth; bullshit; truth; rhetoric; problematology; postmodernism; post-postmodernism; grounds of rationality

\section{ВВЕДЕНИЕ}

Что может послужить основанием рациональности и моральных установок в современном мире - в мире, который уже покинул «состояние постмодерна» с его кризисом оснований, но столкнулся с новыми затруднениями? Чтобы ответить на этот вопрос, в настоящей статье я обращусь к ана- 
лизу постправды как риторического феномена и социально-философского понятия.

В первом разделе я кратко изложу историю появления самого понятия, а затем представлю две контрастирующие концепции постправды, которые были предложены Брюсом Маккомиски и Стивом Фуллером. С точки зрения Маккомиски (ее я освещу более подробно по причинам, которые станут ясны в дальнейшем), постправда представляется сугубо отрицательным феноменом, характерным исключительно для современной эпохи, тогда как Фуллер усматривает в ней также положительный смысл и утверждает, что постправда сопровождала человечество как минимум со времен Платона.

Во втором разделе я обращусь к философской теории представителя Брюссельской школы риторики Мишеля Мейера - так называемой проблематологии - и постараюсь выстроить проблематологический подход к феномену постправды, который был бы избавлен от эксцессов концепций, рассмотренных в первом разделе. Я также опишу, каким образом проблематологическая перспектива может помочь нам разрешить новый кризис оснований.

\section{РИТОРИКА ПОСТПРАВДИВОГО МИРА}

Осенью 2016 г. Оксфордский словарь английского языка ввиду огромной популярности назвал «постправдивый» (post-truth) словом года, дав ему следующее определение: «постправдивый - прилагательное, которое обозначает или указывает на обстоятельства, в которых объективные факты в меньшей степени влияют на формирование общественного мнения, нежели обращения к эмоциям и личным убеждениям» (Word of the year 2016 is... , s/d: Электронный ресурс; здесь и далее перевод мой. - A. M.). По данным словаря, впервые его употребил американский драматург сербского происхождения Стив Тешич в статье 1992 г. для журнала The Nation, в которой он рассуждал, в частности, об Уотергейтском скандале, Иран-контрас и Войне в Персидском заливе, об их освещении в американских медиа и о том, как оно повлияло на отношение американцев к истине и правде. По словам Тешича, американский народ стал отождествлять правду и плохие новости, а поскольку плохие новости ему были не по душе, он стал искать защиты от истины у правительства и СМИ. В конце концов американцы «обрели духовный механизм, позволяющий лишить истину какого бы то ни было значения... будучи свободным народом, мы свободно решили, что желаем жить в своего рода постправдивом мире» (Tesich, 1992: 13).

Рассуждения Тешича перекликаются с заметками Жана Бодрийяра о Войне в заливе, опубликованными ранее в 1991 г., где говорилось о победе симуляции «войны» над истиной «скандала», которым данная «не-война... является на самом деле...» (Бодрийяр, 2016: 87). Однако само слово «пост- 
правда» (вполне соответствующее, по крайней мере на первый взгляд, «состоянию постмодерна» на момент 1990-х гг.) стало активно употребляться лишь в 2010-е гг., в особенности на фоне президентской кампании и дальнейшего избрания Дональда Трампа. В чем же причина того, что пик популярности столь постмодернистского, казалось бы, слова, отсылающего к симуляционности и (добровольно принимаемой, даже желаемой в качестве успокоительного) пропаганде, пришелся на эпоху, которая уже вышла из постмодернизма в «постпостмодернизм», будь то в метамодернизм, космодернизм, диджимодернизм или т. п. (см.: Павлов, 2018; Афанасов, Павлов, 2019; Сафронов, 2019)?

С точки зрения исследователя постправды Брюса Маккомиски, дело состоит в том, что до 2010-х гг. в СМИ и медиа господствовала, скорее, брехня (bullshit), которую исследовал философ Гарри Франкфурт, нежели собственно постправда (McComiskey, 2017: 11). Брехня - не то же самое, что ложь: брехуну вовсе не обязательно лгать - его задача состоит не в искажении фактов или собственного отношения к фактам, а в обмане относительно своих действий и намерений, и потому, как правило, «люди более терпимы к брехне, чем ко лжи...» (Франкфурт, 2008: 85), которую они воспринимают более лично, т. е. как выпад в свою сторону. Кроме того, брехать вполне можно, не зная правды, в то время как ложь предполагает в том или иной форме знание истины (там же: 91). Итак, если позиция брехуна подразумевает безразличие к истине, а позиция лжеца - искажение или же отрицание истины, то постправда характеризуется иной установкой - отвержением не конкретной правды, а истины самой по себе в качестве критерия или стандарта оценки нас и наших суждений. Даже если не выделять постправду как отдельную категорию в противовес брехне (и лжи), брехня изменила свой статус: по мнению Маккомиски, если в мире до Брексита и Трампа аудитория брехни еще сохраняла связь с фактами и действительностью, то в постправдивом мире ей до них нет больше никакого дела (McComiskey, 2017: 12).

Анализ Маккомиски может показаться несколько наивным. Так, разве нельзя продемонстрировать, что наш мир в той или иной мере всегда был постправдивым, как это делает Стив Фуллер, который также посвятил феномену постправды целую книгу (Fuller, 2018)? Тем не менее, если отстраниться от вопросов датировки и присмотреться к самому понятию, на мой взгляд, Маккомиски удается приблизиться к выводу, который сделал Фуллер: существо постправды действительно заключается в рассмотрении истины не как конкретного факта или суждения, но как критерия оценки фактов и суждений, однако это отношение не стоит называть отвержением. Для Маккомиски будто бы существует единая и определенная вселенная, некий «эпистемологический континуум», включающий в себя «достоверные факты, фундамен- 
тальные реалии и всеобщие истины» философии и науки (McComiskey, 2017: 7), отвергаемый постправдой, тогда как для Фуллера постправда указывает на борьбу за установление критериев истины (Фуллер, 2018: Электронный ресурс) - борьбу за само определение этого континуума или же распрю эпистемологических метанарративов. Иными словами, Маккомиски остановился на полпути при переходе от первопорядкового к второпорядковому описанию, будучи в силах представить только присутствие (правда, ложь, брехня до постправды) или отсутствие эпистемологического континуума (постправда), но отнюдь не его становление и не многообразие подобного рода континуумов.

Так, для Маккомиски и Платон, и софисты отталкиваются от единого континуума, находясь в мире до постправды, вот только Платон следует континууму, а софисты отклоняются от него. Для Фуллера же обе стороны бьются за установление своего эпистемологического континуума, так что Платон оказывается постправдивым ничуть не меньше, чем софисты. Обращение к примеру с софистами неслучайно - оба автора так или иначе подходят к теме постправды с точки зрения риторической теории. Но если для Фуллера риторика представляет собой «тигель образов постправды» (Fuller, 2018: 28), то Маккомиски рассматривает феномен постправды с позиций «правдивой» риторики, т. е. риторики, следующей единому континууму, пускай он и отмечает, что со времен Стивена Тулмина и «новой риторики» Хаима Перельмана и Люси Олбрехт-Тытеки риторическая теория располагается в поле практической аргументации и как таковая «отвязывается» от фундаменталистских (в эпистемологическом смысле) притязаний философии и науки (McComiskey, 2017: 7). Он применяет в анализе постправды классические категории античной риторики: если установка постправды заключается в растворении эпистемологического континуума, которое приводит к отрыву языка от реальности и его замыканию на самом себе, отсюда следует, что постправда функционирует за счет подавления логоса (т. е. заключающейся в сообщении аргументации) в пользу этоса (отображения в нем личности говорящего, его репутации, намерений и т. д.) и пафоса (эмоционального воздействия сообщения на аудиторию). Ученый отмечает, что «в мире постправдивой риторики, где все вверх тормашками, этос и пафос сами по себе стали успешными источниками аргументации, тогда как логос на деле подвергнулся обесцениванию» (McComiskey, 2017: 20).

Исходя из словарного определения «постправдивого», можно было бы предположить, что секрет успеха Трампа во многом кроется в его пафосе, обращающемся к эмоциям и убеждениям аудитории, однако, по мнению Маккомиски, его этос ничуть не менее важен. И дело даже не в том, что в речах Трампа отображались те или иные черты его личности, как бы их только 
ни описывали. Наоборот, в его речах отображались просто «какие угодно черты личности, которые могут выиграть в борьбе за риторическую повестку дня» (ibid: 22), поэтому в мире существует ровно столько же Дональдов Трампов, сколько существует аудиторий, причем указание на их несходство не будет иметь негативных последствий, так как «в постправдивом риторическом мире откровенная неблагонадежность может оказаться более ценной личностной чертой, нежели притворная благонадежность» (ibid: 23), особенно если принять во внимание все растущее недоверие даже к тем институциям, что прежде считались поборниками истины и критического мышления. Так, Трампу зачастую достаточно было указать на то, что этосу его критиков недостает логоса, который бы доказывал ложность его заявлений (ibid: 27).

Анализ Маккомиски по большей части наследует традиции типовой критики постмодернистских позиций, в отличие от более благожелательного и менее поверхностного подхода Фуллера, согласно которому постправда вовсе не является «исключительно современной проблемой», коль скоро «феномен постправды всегда был с нами» (Фуллер, 2018: Электронный ресурс). Но, несмотря на неглубокий и бедный в философском отношении инструментарий, именно наивные пресуппозиции Маккомиски, его фундаменталистские притязания, ориентация на реальность и референциальность в противовес языку, замкнутому исключительно на себе, свидетельствуют о том, что понятие постправды, даже будучи пейоративом, принадлежит уже не постмодерну, а условному «постпостмодернизму», т. е. тому, что следует за постмодерном, или по меньшей мере указывает на то, что за ним следует. Вопрос лишь в том, что же лучше всего подходит на роль «основания», «реальности» или «референта».

\section{ПРОБЛЕМАТОЛОГИЧЕСКАЯ ПАРАДИГМА}

В письме Томасу Э. Кэрролу от 15 мая 1982 г. (вошедшем в состав сборника «Постмодерн в изложении для детей») Жан-Франсуа Лиотар писал: «Я прочитал одного молодого бельгийца, специалиста по философии языка: он сетует, что европейская мысль в ответ на вызов, который ей бросают языковые машины, оставила этим последним на произвол, как он считает, заботу о реальности, что парадигму референциальную она заменила адлингвистической (говорят о сказанном, пишут о написанном, интертекстуальность); теперь, он полагает, самое время вновь накрепко укоренить язык в референте» (Лиотар, 2008: 12). Этим бельгийским философом языка был Мишель Мейер (Turnbull, 2010: 59-60), представитель Брюссельской школы риторики, ученик Хаима Перельмана и создатель оригинальной философской версии «новой риторики» - проблематологии. Прежде чем объяснить основные положения проблематологии и то, как Мейер предлагает «вновь накрепко укоре- 
нить язык в референте» с тем, чтобы выстроить проблематологический подход к теме постправды, нам следует кратко осветить некоторые тезисы Перельмана, к которым зачастую обращается Маккомиски, будь то открыто в других работах (например, McComiskey, 2015: 85-86, 128ff) или подспудно в изложенном мной анализе, и которые Мейер подвергает критике.

Перельман известен своим делением аудитории на универсальную и конкретную. Как таковая аудитория делится на три типа - на универсальную аудиторию, которую составляют «все человечество или как минимум все нормальные взрослые люди», на собеседника оратора и, наконец, самого оратора в его размышлении с самим собой, причем последние два всегда воплощают либо универсальную, либо конкретную аудиторию (Perelman, Olbrechts-Туteca, 1969: 30). Универсальная аудитория есть не что иное, как мысленная конструкция оратора, и у каждой культуры или индивида имеются свои представления об универсальной аудитории (ibid: 63), однако каждую такую конструкцию можно рассматривать в качестве конкретной аудитории; тем не менее мы могли бы сказать, что у каждого оратора существует аудитория, которая выходит за пределы его конкретной аудитории, служа для аргументации чем-то наподобие строительных лесов. Дело в том, что универсальная аудитория, состоящая из всех разумных агентов, мыслится как обращенная к доказательству, подкрепленному объективными данными, в то время как конкретная аудитория требует не только доказательства, но и убеждения, которое учитывает ее характер. Иными словами, универсальная аудитория выступает идеальным носителем того эпистемологического континуума, о котором писал Маккомиски.

По мнению Мейера, универсальная аудитория оказывается весьма спорным понятием, поскольку она подрывает сам проект «новой риторики», суть которого заключается в отстранении от картезианского разделения знания на рационально-аподиктическое и эмоциональное. Для Перельмана предметом риторики становится не рациональность и не эмоциональность, но рассудительность как категория аргументов, которые пусть и не имеют силу доказательств, но все же направлены на убеждение аудитории и отличны от чисто аффективных средств. Однако универсальная аудитория чересчур походит именно на скопление рациональных, а не рассудительных агентов; пусть «новая риторика» и отходит от модели дедуктивных и эмпирических наук, она всегда держит их в уме. Эмоциональность же рассматривается в ней как нечто иррациональное в принципе, т. е. Перельман, в сущности, выкидывает из своей теории анализ страстей и эмоций, отказывая им в какой бы то ни было логике - ему интересно лишь то, что можно озвучить пускай не в научном труде, но в зале суда (Meyег, 2010: 404-406). Нетрудно увидеть, что в таком варианте риторика оказывается неполной, поскольку она должна 
учитывать не только случай рассудительной дискуссии, подразумевающей конфликт и его разрешение или неудачу в разрешении, но также все остальные коммуникативные ситуации.

Кроме того, Перельман, как и другие последователи аристотелевской риторической традиции, считает, что под вопросом в дискуссии находится тезис, тогда как Мейер полагает, что «под вопросом» в дискуссии и любой иной коммуникативной ситуации находится сам вопрос, на который этот тезис отвечает; иными словами, ее предмет — проблема (ibid: 406). Именно превращение риторики в проблематологию позволяет ей стать уже полной теорией, причем теорией философской - и даже метафизической: полемизируя с постмодернистами, возвещающими закат рациональности и ставящими под вопрос ее первые основания, которые составляют предмет метафизики, Мейер решился утверждать, что само вопрошание о такого рода принципах и должно выступать основанием, ведь в вопросе о том, что является первым (принципом), первым является сам вопрос. Как только мы это принимаем, нам становится ясно, как действовать: следует определить, какие перед нами стоят проблемы, какие вопросы стоило бы задать, какие из них имеют решение, а какие являются неразрешимыми, и т. д. (Turnbull, 2005: 186). Если же мы не принимаем декларацию Мейера о первичности вопрошания, мы ставим ее под вопрос - и потому лишь вновь утверждаем ее ${ }^{1}$ (Meyer, 1995: 18). Именно проблемы оказываются у Мейера тем самым «референтом», в котором требуется укоренить наш язык и коммуникацию в целом, включая нашу практику, ведь всякий раз, когда мы что бы то ни было говорим или делаем, мы занимаемся решением проблем, даже если не задаем вопросы в явном виде. Значение есть не что иное, как отношение «вопрос - ответ», представляющее собой проблематологическое различие имплицитных проблем и эксплицитного дискурса о них (ibid: 206).

Эпистемологический континуум и универсальная аудитория, таким образом, оказываются спорными понятиями, поскольку их использование подразумевает ориентацию исключительно на сами высказывания, тезисы, т. е. ответы и решения, а вовсе не на стоящую за ними проблематику. Мейер называет такую ориентацию пропозиционализмом. Вот почему для Маккомиски и Перельмана логос имеет большее значение, нежели этос и пафос. Для Мейера же три составляющих должны располагаться на одном уровне и равной опоре, которой служит проблематичность: «Риторика - это преодоление дистанции (или различия) между индивидами (этос и пафос) по данному вопросу (данному через логос)» (Meyer, 2010: 408). Этос для Мейера

\footnotetext{
${ }^{1}$ Есть некоторая ирония в том, что письмо, в котором Лиотар обронил свою краткую критическую ремарку о Мейере, озаглавлено вполне проблематологически — «Ответ на вопрос: что такое постмодерн?».
} 
представляет собой ответственность, причем буквально - как способность оратора отвечать, будь то своими ответами или за свои ответы либо решения. Если этос — инстанция Я, то пафос - инстанция Другого: это аудитория, «воодушевленная вопросами... отвечающими на более фундаментальные проблемы, глубинными субъективными выражениями которых служат эмоции и даже страсти» (ibid: 409). Что до логоса, то он служит выражением самого проблематологического различия между вопросами и ответами — это инстанция Мира, сочленяющая Я и Другого. Поскольку Я и Другой соединены в Мире, они не менее реальны, чем он, и тем не менее Перельман с Маккомиски - как пропозиционалисты - это упускают. Пропозиционализм, по словам Мейера, всегда предполагает четко заданную онтологию, выписанную будто бы из ниоткуда, из нулевой перспективы, принадлежащей не Я и не Другому, а некой универсальной аудитории, которая как раз не существует, представляя собой абстракцию, а не реальность. Именно эта онтология требует, чтобы истина была чем-то однозначным, необходимым, исключающим свои альтернативы в качестве ложных и «проблематичных» (Meyer, 1988: 255). Мейер отвергает такую онтологию (стоит отметить, что, по его мнению, он отказывается от онтологии как таковой) в пользу метафизики, основанной на интеррогативности.

Отсюда еще не следует, что тем самым Мейер устраняет всякое различие между истиной и ложью или между буквальным и метафорическим, к примеру. Напротив, для него чрезвычайно важно сохранять различия; однако вместо того, чтобы отдавать первенство одной из двух противоположностей, он приоритизирует отношение между ними и релятивизирует сами термины. Так, если постмодернисты представляют буквальное в качестве отклонения от фигуративного, говоря о вездесущности метафоры, а их критики проделывают обратное, то Мейер настаивает на том, что ни буквальное, ни фигуративное нельзя назвать первоэлементом, поскольку буквальность и фигуративность представляют собой не субстанциональные свойства, а функции значения, определяемые его проблематологическим различием: выражение является буквальным, если снимает вопрос, на который эксплицитно отвечает, и фигуративным, если имплицитно поднимает другой вопрос, на который также отвечает, и оно вполне может быть тем и другим, но разница между функциями никак при этом не устраняется (Meyer, 1995: 241; Yarbrough, 2007). Проблематологическое различие обуславливает, с точки зрения Мейера, и деление риторики на отрицательную, или черную, и положительную, или белую. Первая риторика действует так, как будто бы имплицитные проблемы были решены, вторая же сохраняет проблематичность и проясняет ее, a не утаивает, предоставляя пространство для дальнейших вопросов (Turnbull, 2014: 122). Черная риторика оставляет аудиторию на первопоряд- 
ковом уровне заранее установленного эпистемологического (или иного) континуума, тогда как белая приглашает аудиторию к участию в его формировании или переопределении.

\section{ЗАКЛЮЧЕНИЕ}

Где же в проблематологической парадигме оказывается постправда? На мой взгляд, по обе стороны. С одной стороны, постправда целиком укладывается в черную риторику идеологии (которая ведет себя так, как будто может дать ответ на все вопросы), пропаганды (которая ведет себя так, как если бы она уже дала ответы на все вопросы, и больше вопросов не предвидится) и т. п. С другой стороны, постправдивость вшита и в белую риторику, которая берет в расчет соединяющие оратора и аудиторию вопросы вкупе с сопровождающими их эмоциями и страстями, поскольку этос и пафос с их решениями и проблемами ничуть не в меньшей степени являются фактами и реалиями, чем логос. Поэтому проблематология и ее логика, этика и «патетика» предоставляют основание не только для нашей рациональности, но и для духовно-нравственных ценностных установок в постпостмодернистском миpe.

\section{СПИСОК ЛИТЕРАТУРЫ}

Афанасов, Н. Б., Павлов, А. В. (2019) Образы современности в XXI веке: космодернизм // Знание. Понимание. Умение. № 2. С. 46-62. DOI: 10.17805/zpu.2019.2.4

Бодрийяр, Ж. (2016) Дух терроризма. Войны в заливе не было / пер. с фр. А. Качалова. М. : РИПОЛ Классик. 224 с.

Лиотар, Ж.-Ф. (2008) Ответ на вопрос: что такое постмодерн? // Лиотар Ж.-Ф. Постмодерн в изложении для детей. Письма 1982-1985 / пер. с фр., примеч. и общ. ред. А. В. Гараджи. М. : Рос. гос. гуманит. ун-т. 145 с. С. $11-$ 32.

Павлов, А. В. (2018) Образы современности в XXI веке: метамодернизм // Логос. Т. 28. № 6 (127). С. 1-19. DOI: 10.22394/0869-5377-2018-6-1-16

Сафронов, Э. Е. (2019) Что будет вместо постмодерна? Диджимодернизм как культурная доминанта // Galactica Media: Journal of Media Studies. T. 1. № 1. C. 178-195. DOI: 10.24411/2658-7734-2019-00010

Франкфурт, Г. Г. (2008) К вопросу о брехне / пер. с англ. М. Ослопа ; под ред. Г. Павловского, И. Чечель. М. : Европа. 120 с.

Фуллер, С. (2018) Постправда [Электронный ресурс] // ПостНаука. 18 апреля. URL: https://postnauka.ru/longreads/84059 [архивировано в Wayback Machine] (дата обращения: 22.06.2019). 
Fuller, S. (2018) Post-truth. Knowledge as a power game. L. ; N. Y. : Anthem Press. x, 208 p. DOI: 10.2307/j.ctvgd30v

McComiskey, B. (2015) Dialectical rhetoric. Logan, UT : Utah State University Press. xiv, $222 \mathrm{p}$.

McComiskey, B. (2017) Post-truth rhetoric and composition. Logan, UT : Utah State University Press. v, 52 p. DOI: 10.2307/j.ctt1w76tbg

Meyer, M. (1988) The rhetorical foundation of philosophical argumentation // Argumentation. Vol. 2. Issue 2. P. 255-269. DOI: $10.1007 / B F 00178025$

Meyer, M. (1995) Of problematology: Philosophy, science, and language / transl. by D. Jamison, in collaboration with A. Hart. Chicago ; L. : University of Chicago Press. vii, 310 p.

Meyer, M. (2010) The Brussels school of rhetoric: From the new rhetoric to problematology // Philosophy \& Rhetoric. Vol. 43. No. 4. P. 403-429. DOI: 10.1353/par.2010.0007

Perelman, Ch., Olbrechts-Tyteca, L. (1969) The new rhetoric: A treatise on argumentation / transl. [from the French] by J. Wilkinson, P. Weaver. Notre Dame, IN ; L. : University of Notre Dame Press. x, 566 p.

Tesich, S. (1992) A government of lies // The Nation. Vol. 254. Issue 1. P. $12-14$.

Turnbull, N. (2005) Policy in question: From problem solving to problematology : PhD thesis. Sydney : University of New South Wales, School of Social Science and Policy. iv, 415 p.

Turnbull, N. (2010) The problematological foundation of reason in postmodernity // Revue Internationale de Philosophie. No. 1 (251). P. 59-77.

Turnbull, N. (2014) Michel Meyer's problematology: Questioning and society. L. ; N. Y. : Bloomsbury. xi, 199 p.

Word of the year 2016 is... (s/d) [Электронный pecypc] // Oxford Dictionaries. URL: http://languages.oup.com/word-of-the-year/word-of-the-year-2016 [apхивировано в WaybackMachine] (дата обращения: 22.06.2019).

Yarbrough, S. R. (2007) As you like it: Michel Meyer's metaphor // Revue Internationale de Philosophie. No. 4 (242). P. 377-390.

Дата поступления: 25.06.2019 г.

\section{REFERENCES}

Afanasov, N. B. and Pavlov, A. V. (2019) Obraztsy sovremennosti v XXI veke: kosmodernizm [Images of modernity in the twenty-first century: Cosmodernism]. Znanie. Ponimanie. Umenie, no. 2, pp. 46-62. (In Russ.). DOI: $\underline{10.17805 / z p u .2019 .2 .4}$ 
Baudrillard, J. (2016) Dukh terrorizma. Voiny v zalive ne bylo [L'Esprit du terrorisme. La Guerre du Golfe n'a pas eu lieu / The spirit of terrorism. The Gulf War did not take place] / transl. from French by A. Kachalov. Moscow : RIPOL Classic Publ. 224 p. (In Russ.).

Lyotard, J.-F. (2008) Otvet na vopros: chto takoe postmodern? [Reponse a la question : qu'est-ce que le postmoderne? / Answering the question: What is the postmodern?]. In: Postmodern v izlozhenii dlia detei. Pis'ma 1982-1985 [Le postmoderne expliqué aux enfants. Correspondance 1982-1985 / The postmodern explained to children. Correspondence 1982-1985] / transl. from French, notes and ed. A. V. Garadzhi. Moscow : Russian State University for the Humanities Publ. 145 p. Pp. 11-32. (In Russ.).

Pavlov, A. V. (2018) Obrazy sovremennosti v XXI veke: metamodernizm [Images of modernity in the twenty-first century: Metamodernism]. Logos, vol. 28, no. 6 (127), pp. 1-19. (In Russ.). DOI: 10.22394/0869-5377-2018-6-1-16

Safronov, E. E. (2019) Chto budet vmesto postmoderna? Didzhimodernizm kak kul'turnaia dominanta [What will happen instead of postmodern? Digimodernism as a cultural dominant]. Galactica Media: Journal of Media Studies, vol. 1, no. 1, pp. 178-195. (In Russ.). DOI: 10.24411/2658-7734-2019-00010

Frankfurt, H. G. (2008) K voprosu o brekhne [On bullshit] / transl. from English by M. Oslop ; ed. by G. Pavlovskiy, I. Chechel. Moscow : Europe Publ. 120 p. (In Russ.).

Fuller, S. (2018) Postpravda [Post-truth]. PostNauka, April 18. [online] Available at: http://postnauka.ru/longreads/84059 [archived in WaybackMachine] (accessed 22.06.2019). (In Russ.).

Fuller, S. (2018) Post-truth. Knowledge as a power game. London; New York : Anthem Press. x, 208 p. DOI: 10.2307/j.ctvgd30v

McComiskey, B. (2015) Dialectical rhetoric. Logan, UT : Utah State University Press. xiv, $222 \mathrm{p}$.

McComiskey, B. (2017) Post-truth rhetoric and composition. Logan, UT : Utah State University Press. v, 52 p. DOI: 10.2307/j.ctt1w76tbg

Meyer, M. (1988) The rhetorical foundation of philosophical argumentation. Argumentation, vol. 2, issue 2, pp. 255-269. DOI: $10.1007 / \mathrm{BF} 00178025$

Meyer, M. (1995) Of problematology: Philosophy, science, and language / transl. by D. Jamison, in collaboration with A. Hart. Chicago ; London : University of Chicago Press. vii, $310 \mathrm{p}$.

Meyer, M. (2010) The Brussels school of rhetoric: From the new rhetoric to problematology. Philosophy \& Rhetoric, vol. 43, no. 4, pp. 403-429. DOI: 10.1353/par.2010.0007 
Perelman, Ch. and Olbrechts-Tyteca, L. (1969) The new rhetoric: A treatise on argumentation / transl. [from the French] by J. Wilkinson, P. Weaver. Notre Dame, IN ; London : University of Notre Dame Press. x, 566 p.

Tesich, S. (1992) A government of lies. The Nation, vol. 254, issue 1, pp. $12-14$.

Turnbull, N. (2005) Policy in question: From problem solving to problematology : PhD thesis. Sydney : University of New South Wales, School of Social Science and Policy. iv, 415 p.

Turnbull, N. (2010) The problematological foundation of reason in postmodernity. Revue Internationale de Philosophie, no. 1 (251), pp. 59-77.

Turnbull, N. (2014) Michel Meyer's problematology: Questioning and society. London ; New York : Bloomsbury. xi, 199 p.

Word of the year 2016 is... (s/d) Oxford Dictionaries. [online] Available at: http://languages.oup.com/word-of-the-year/word-of-the-year-2016 [archived in WaybackMachine] (accessed 22.06.2019).

Yarbrough, S. R. (2007) As you like it: Michel Meyer's metaphor. Revue Internationale de Philosophie, no. 4 (242), pp. 377-390.

Submission date: 25.06.2019.

Морозов Артем Владимирович - младший научный сотрудник сектора социальной философии Института философии РАН. Адрес: 109240, Россия, г. Москва, ул. Гончарная, д. 12, стр. 1. Тел.: +7 (495) 697-98-93. Эл. адрес: morozov.socphil@yandex.ru

Morozov Artem Vladimirovich, Junior Researcher, Department of Social Philosophy, Institute of Philosophy, Russian Academy of Sciences. Postal address: Bldg. 1, 12 Goncharnaya St., 109240 Moscow, Russian Federation. Tel.: +7 (495) 697-98-93. E-mail: morozov.socphil@yandex.ru

Для циитирования:

Морозов A. B. Ответ на вопрос: что такое постправда? Перспектива проблематологии [Электронный ресурс] // Горизонты гуманитарного знания. 2019. № 3. C. 93-105. URL: http://journals.mosgu.ru/ggz/article/view/1048 (дата обращения: дд.мм.гггг). DOI: 10.17805/ggz.2019.3.8 